\title{
The business of integrative medicine in a large hospital system
}

\author{
Thomas Lanni ${ }^{1}$, Gail Elliott Patricolo ${ }^{2}$ \\ 1. Oncology, Medicine, and Imaging, Beaumont Health System, United States. 2. Integrative Medicine, Beaumont Health \\ System, United States.
}

Correspondence: Thomas Lanni, MBA, FACHE. Address: Beaumont Cancer Institute, Oakland University-William Beaumont Hospital School of Medicine, 3601 West Thirteen Mile Road, Royal Oak, MI 48073, United States. E-mail: Thomas.Lanni@beaumont.edu

Received: October 24, 2013

DOI : $10.5430 /$ jha.v3n3p52

\author{
Accepted: January 1, 2014 \\ Online Published: January 10, 2014 \\ URL: http://dx.doi.org/10.5430/jha.v3n3p52
}

\section{Abstract}

The number of patients seeking complementary and alternative medicines combined with conventional treatments has grown considerably over the past decade. To meet the growing demand, a dedicated oncology integrative medicine program was initiated in the Beaumont Health System to address the needs of this patient population. Due to its resounding success and patient satisfaction, as evidenced by patient utilization and testimonials and physician referrals, the program was expanded across the healthcare system to every medical specialty. This study outlines how the program was implemented and its business model.

A number of methods were used to evaluate the feasibility of starting the program and determine the services required. Financial analyses were developed to understand the costs associated with starting the program without financial assistance.

In 2006, an Integrative Medicine program was launched in the Beaumont Cancer Institute (Royal Oak, MI). The initial offering for patients was clinical massage; however, the program rapidly expanded. Currently, services include clinical massage, a clinical massage training program, Reiki, guided imagery, acupuncture, and naturopathic medicine. Patients and physicians expressed satisfaction with the increasing number of complementary services offered at the institution, and the services are heavily utilized. In 2012, the program had more than 18,000 patient visits, of which, 10,191 were for clinical massage, 6,515 for acupuncture, and 1,030 for naturopathic medicine.

In this study of developing and implementing an Integrative Medicine program in a large healthcare system, it is shown that a successful program could be initiated with the appropriate planning and support from administration. The program is shown to be financially viable, as the Integrative Medicine (IM) department has become self-sufficient and no longer requires financial support from other hospital departments, and the numerous testimonials indicate that the program has been rewarding for practitioners, staff, and patients.

\section{Key words}

Integrative medicine, Business, Holistic, Complementary, Health care 


\section{I ntroduction}

\subsection{Why integrative medicine?}

What is Integrative Medicine (IM)? This question is often confusing because the practice can be called many different things. Sometimes, it is called Complementary Medicine, sometimes Complementary and Alternative Medicine (CAM), as initially classified by the National Institute of Health (NIH), sometimes Integrative Medicine, and sometimes Holistic Medicine. The term "holistic" means that humans are more than their physical bodies. Of course, people are physical beings but they are also emotional and psychological beings, and many people say that they are spiritual beings as well. When someone becomes ill, traditional medicine concentrates on healing the physical body, while IM helps patients safely integrate holistic medicine modalities with their exceptional medical care. Traditional medicine must "measure and

calibrate the patient's disease” ${ }^{[1]}$. However, it must be recognized that people are not statistics; they are whole beings. IM services treat the entire person: mind, body, and spirit.

Why would a hospital system want to add IM to their patient offerings? For several reasons, the most important being because patients are seeking and using it. CAM has been described as a patient-driven initiative ${ }^{[2]}$; in other words, consumers are demanding CAM. The 2010 Complementary and Alternative Medical Survey of Hospitals found that 42\% of responding hospitals offered one or more CAM services; patient demand was the number one reason cited for offering a CAM service, followed by its clinical efficacy ${ }^{[3]}$. People in today's day and age want to feel empowered, and they are proactive with regard to their health ${ }^{[4]}$. People no longer blindly follow their physician's advice without question. Patients scour the Internet for information on health and disease states. Children are being raised to be critical thinkers and to ask questions. As well, there is a growing trend towards holistic lifestyles and organic food, as can be seen by the success of the natural and organic grocery chain Whole Foods Stores, a company that successfully competes with mainstream grocery stores ${ }^{[5]}$.

We also know from National Study statistics that patients withhold information regarding their IM use from their physicians to avoid being judged or criticized ${ }^{[4]}$. Patients often feel more comfortable discussing CAM use in IM settings, where they feel the staff will be more open to holistic approaches. We know that patients are using CAM, and they are spending a significant amount of money to do so. A recent Nutrition Business Journal report states that IM revenues now represent 2\% of the \$2.5T spent annually on national healthcare. According to the National Center for Complementary and Alternative Medicine (NCCAM), $40 \%$ of the United States population used some type of complementary and alternative therapies and products during 2007 alone ${ }^{[6]}$.

IM programs are attractive to patients and can increase patient satisfaction; therefore, by adding these services, hospitals stay competitive and stand out from the crowd ${ }^{[7]}$. Adding to all of these reasons is the new, evolving issue of Health Care Reform in the US. With its focus on prevention and wellness, it follows that health care providers will be taking a closer look at holistic approaches to health.

\subsection{The seed of an idea}

It is our system's experience that developing and sustaining an IM program is not only feasible but also desirable and has many benefits for a hospital system. We also feel it is important for organizations to share their challenges and successes in this unique medical field so that we can learn from each other and offer our patients the very best holistic care.

Our program had its birthplace in oncology. Cancer Centers are ideal places to start programs of this type as different aspects of IM are present in most cancer centers ${ }^{[8]}$ since it is not unusual for cancer centers to offer massage, meditation, or yoga. A whole new field of "Integrative Oncology" is evolving: "It is a synthesis of mainstream cancer treatment and complementary therapies. Complementary therapies are non-invasive, non-pharmacologic adjuncts to mainstream cancer treatment. These therapies do not directly affect or treat the disease. Instead, they help relieve pain and distress” ${ }^{[8]}$. 
In 2004, the Medical Director of Oncology in our organization sought to create an IM program to complement the established cancer program, which included genetic counseling, lymphedema clinics, oncology dieticians, social workers, and multi-disciplinary clinics. For programs of this type to be successful, they not only need strong medical champions but also administrative support at the executive level. The champion(s) bring credibility to an IM program that is initiated in a traditional hospital setting, acquiring respect for a program that might otherwise be regarded with suspicion from medical professionals and top-level executives within an organization. Others agree that a champion within the institution is critical for an IM program to succeed ${ }^{[9]}$. However, in addition to garnering respect, the champions must have the influence within the organization to get things accomplished.

In addition to medical and administrative champions, a strong manager with not only IM knowledge but also strong business skills and acumen is required to direct the program ${ }^{[9]}$. IM is not just a clinical program but also is often referred to as "retail medicine"; therefore, a manager must understand how to run a business and have tenacity, creativity and business savvy.

Because there was no other CAM services offered in the system, our program was truly grassroots, and we did not have to deal with competition or a dilution of our efforts. We chose to name this new oncology offering "Integrative Medicine" integrating the best of both worlds of great traditional medical care with holistic mind-body medicine. An in-depth business plan was developed that outlined the program in several different phases. Modalities were chosen carefully with evidence-based research support. Initially, the program was housed in the Cancer Center at the 1,070-bed flagship hospital.

Not only did it make sense to start in Oncology because of the receptive patient population, but oncology also offered the program a place to grow as part of a larger department. This situation allowed the IM department a certain amount of freedom within oncology as well as permitted the program to grow by shifting costs; any losses were absorbed by the larger departmental framework. This situation is important when creating a program from the ground up. All services were offered to cancer patients, survivors, loved ones, caregivers, and oncology staff with the belief that everyone who touches the life of a cancer patient needs support.

\section{Conditions}

\subsection{The groundwork}

Before having a functional IM department, hours were spent consulting with Corporate Compliance, Legal, Cash Handling, and Safety - all experts to help set the program up properly and within hospital governance standards. Because this type of program had not been previously offered in the system, many unique processes needed to be developed such as creating patient waivers, charting forms appropriate for IM, and a cash collection system. We felt that if the initial implementation process was not properly considered, the program would fail.

Due to the hospital system's conservative medical views, the program was introduced "gently", starting with offering cancer patients oncology massage, guided imagery, group meditation, yoga, and Tai Chi. These modalities are noninvasive and mainstream and added to the hospital's prestigious reputation without detracting from it. During this start-up period, extensive educational sessions were provided to medical oncologists, radiation oncology physicians, nurses, residents, fellows, social workers, and physical therapists. The educational sessions were in the form of seminars, "lunch and learns", and one-on-one meetings. The CAM modalities were presented in an evidence-based way, and it was explained how they could be safely incorporated into patient care. This education is necessary to enlist the support of the different hospital staff members and encourage collaboration ${ }^{[9]}$. Within months, the hours of operation were extended, and more therapists were hired. In addition, after one and a half years of operation, acupuncture was added to the service line as well as cranial sacral therapy and reflexology. 
As the department became known in the hospital, other physicians in the organization expressed their pleasure that the hospital was offering IM by calling the IM department and referring their patients to the program. It had to be explained that their patients could not be accepted unless they were cancer patients. Medical professionals from other specialties such as cardiology, urology, gastroenterology, and gynecology became interested in the program, and some physicians expressed frustration that their patients could not access these services. What was such a positive for the Oncology Department had become a negative for others. When this dilemma was presented to medical and hospital administration, it was decided to open IM to all patients after just one full year in oncology.

A snowball effect occurred where the IM center became so busy that acupuncture had to be moved to a different space in a medical office building on the hospital property. At the same time, the smaller 458-bed, sister hospital desired an IM program; therefore, a small, three-room suite was painted and furnished. The initial education process for the main hospital had to be repeated for the smaller one. Similar to experiences at other institutions, "time was needed to establish the level of trust necessary to fully integrate the CAM services into the host institutions" ${ }^{[9]}$. Although, hospital systems can be very bureaucratic, we experienced almost no resistance. All expansion remained under the management and oversight of the parent IM program, allowing for continuity and quality of care.

Four years after establishment, the IM program was a legitimate, respected member of the health care community; members of the IM department were requested to present their work at conferences and department meetings. In addition, physicians were referring patients to the IM department, thus indicating that physicians felt confident sending their patients to the IM department for care. Because of the success of the IM program at that time, naturopathic medicine was also piloted and established to a tremendous patient response. "Naturopaths", "naturopathic doctors" or "natural medicine doctors" are highly trained health care providers who offer leading-edge co-management or complementary management for primary care health issues. The educational track for earning a doctorate in natural medicine (N.D.) is analogous to earning a doctorate in medicine with a key difference that reflects scope of practice. The scope includes clinical nutrition, vitamins and minerals, botanical therapies, mind-body medicine and health behavioral counseling ${ }^{[10]}$.

Growing organically with slow, calculated steps allowed the IM department to be adaptable. Unlike other centers that

failed because they had significant financial expenditures and were pushed to expand too rapidly ${ }^{[4]}$, we believe we were successful because we started with no significant outlay of money and stayed as lean and flexible as possible.

The program continues to expand into multiple sites. We now have four IM clinics and treatment rooms designed and designated for IM in other medical specialties such as Women's Urology, Women's Cardiology, and the Vein Clinic.

\subsection{Space - "the 5-letter word"}

Finding space was a challenge, as it is in many hospital systems. Our space experience has been quite varied. The original clinic in oncology was a retrofitted infusion area. It was started on a tight budget with fresh paint and mostly donated art and furniture. It created a homey feel, which the cancer patients appeared to enjoy. The cancer center was a familiar place for these patients, with ease of access from their traditional treatments. However, for the non-cancer patient, it was not ideal, as many people associate the cancer center with illness and feel uncomfortable in a waiting area with the critically ill ${ }^{[4]}$. Although we had a few complaints regarding our cancer center IM space, we were fortunate to have it with space at a premium. More importantly, many clients expressed confidence about coming to the hospital for their IM services, even if it was in the cancer center. Housing an IM department within a hospital lends credibility to the program that is not afforded to a stand-alone location. Patients that might otherwise be wary of CAM treatments may be more likely to try them if offered in a hospital-based IM department ${ }^{[4]}$. Space has been viewed as a barrier for other centers as well: "challenges finding appropriate space where the entire team can be housed together...we call 'space' the five-letter word!” ${ }^{[9]}$. As mentioned, the acupuncture program grew so rapidly that it was moved to its own space in a medical building. This is not ideal for an integrated multi-disciplinary vision but has been unavoidable. 
After less than two years in the smaller, 458-bed hospital, the system built a large seven-treatment room IM space in a new medical office complex connected to the hospital. We worked with architects and interior designers to create a comfortable setting with soft lighting, comfortable chairs, and soothing artwork. The space was strategically located next to the cancer center for ease of access but not in it, for non-cancer patients. The growth in this new space has been so rapid that we are currently overflowing.

In 2011, the health system built another large, 98,000-sq. foot ambulatory center that focuses on rehabilitation care and wellness. This state-of-the-art building housed physical and occupational therapy, a pain clinic, weight control, an orthopedic physician group and a full-line, 40,000-sq foot health club. It was decided that IM would have a visible suite on the first floor. With this center only $1 / 8$ of a mile from the hospital, there was concern that this facility would take IM clients from the hospital. However, that situation did not occur. With strategic marketing, the rehabilitation center has attracted a very different patient population. Whereas the IM program at the hospital primarily treats patients with varying degrees of illness, the ambulatory center assists clientele that require rehabilitation and wellness. With an emphasis on neuro-muscular health, this facility focuses on orthopedic cases, athletes, and sports-related injuries.

\subsection{The right people for the job}

We believe staffing is a pivotal issue for success. Not only do you need a strong manager/director to run the program, finding the right practitioners to be a part of the IM is critical ${ }^{[9]}$. The IM practitioners must not only be competent, they must also be suited to a hospital-based practice. A hospital-based practitioner will see very different types of clients from a private practice or spa environment. Patients have varying degrees of illness, and special accommodations are required to ensure that the CAM therapy is helpful and does not cause harm. Practitioners must be knowledgeable about the patient's condition, diagnosis, treatment, and side effects that may result from their treatment ${ }^{[11]}$. In addition, dealing with the critically ill or dying patient is emotionally draining and not for everyone.

Practitioners must also be able to gain the trust of the medical staff by appearing and communicating professionally. They must be able to work as an integrative team with other CAM providers as well as the hospital staff ${ }^{[9]}$. In addition, the IM staff must learn the hospital's Electronic Medical Records system. Table 1 indicates the practitioners on staff at the Beaumont Integrative Medicine Department in 2013. Many of the IM practitioners are part-time employees due to the nature of the work; for example, a massage therapist cannot safely provide massages for 40 hours a week. The 52 practitioners listed in Table 1 are equivalent to 32.3 full-time employees.

Table 1. Practitioner staff in 2013 - beaumont integrative medicine department

\begin{tabular}{ll}
\hline Clinical Massage Therapists/Cranial & \\
\hline Sacral Therapists/Reflexologists/Reiki & 32 \\
Physician Acupuncturist & 1 \\
Traditional Chinese Medicine Acupuncturists & 8 \\
Naturopathic Doctors & 3 \\
Guided Imagery Specialist & 1 \\
Reiki Volunteers & 7 \\
TOTAL & 52 \\
\hline
\end{tabular}

\subsection{Getting the word out}

The goal of marketing any program relies on the commitment of the department and organization to inform the community at large about this new program. The forum for which that happens is dependent on the capabilities of the organization. When the planning of the IM program started, it was decided to review the competitive landscape locally and evaluate how other academic centers have proceeded to offer these services to the public. Since the inception of the program, the initial business marketing plan has been changed multiple times as the economy shifts, healthcare reform evolves, and services 
and locations expand. Having a vision and a well-defined business is critical to ensuring that any program is successful from the onset and into the future. To reach clients locally and regionally, the team must define the market (primary and secondary) and what strategies will be used to reach these individuals. In addition, flexibility is a must considering the changing financial landscape and the advancements in technology.

When the IM program was launched at Beaumont Health System, internal marketing was the first focus, not just because the health system already had thousands of potential clients but also because it was cost effective. Many internal resources were used to help spread the word around the hospital community. These resources included newsletters, electronic calendar announcements, presenting at Professional Nurse Council meetings, physician staff meetings, conferences, support groups, and leadership meetings. The was goal was to present information to as many colleagues as possible not only to make people aware of the services but also to dispel any myths that could exist regarding IM. While meeting with these groups, we also utilized the hospital's community relations and public relations experts to identify groups to speak to and story ideas for potential media hits within our community at large.

More recently, the advent of social media forums has allowed the program to reach a larger audience who might not otherwise be aware of the services. Social media such as Facebook, Twitter, LinkedIn, Pinterest, and others have allowed information either small or large to reach a wider audience locally, regionally, and even nationally. The availability for this type of forum is due to a healthcare system's willingness to change with the times and be a leader within the healthcare arena. This was shown to be true when Beaumont Health System was ranked \#11 in the 2013 Top 50 Most Social Friendly Hospitals ranking ${ }^{[12]}$. The marketing team has allowed IM the forum to create its own dedicated Facebook page to update its "friends" on new class offerings, new treatments, and any information that a person might need to gain an understanding of the program. These social media forums are also directly linked to the health system website so that potential customers have the ability to gain more knowledge about not only IM but also allow them to become more familiar with the other services offered at the institution.

Other avenues used to share information is the hospital website and email blog. These forums provide more in-depth information about the IM program and the services offered throughout the system so patients have the opportunity to see a specialist at a convenient location. Although these avenues are not as quickly updated as other social media sites, they still provide an opportunity to share content regarding different services, allowing patients to have a better understanding of what services they are seeking. This adoption of information sharing has allowed patients and our community to understand the services provided not only in IM but also the entire health system. Of course, the best advertising is that of pleased patients: "the most telling evaluation of any medical model is whether patients deem their care or provider worthy of referring to others" ${ }^{[4]}$. Our data show that from January 2005 to December 2012, word of mouth represented $76 \%$ of the referral pattern to IM.

\subsection{Who we serve}

Our patient base is varied, with women representing $80 \%$ of the clients. We do have many elderly patients that are on Medicare but choose to pay for IM as their "last resort" for pain issues. Many clients are highly educated people who read about IM and want to experience it. Some are critically ill such as our cancer patients, and then there are others who believe in creating a holistic, balanced approach to wellness. Although the program originated in Oncology, cancer patient appointments now account for approximately 7\% of the 18,196 total patient appointments in 2012 (see Table 2).

Table 2. Integrative medicine clientele at beaumont health system - 2008-2012

\begin{tabular}{llllll}
\hline & $\mathbf{2 0 0 8}$ & $\mathbf{2 0 0 9}$ & $\mathbf{2 0 1 0}$ & $\mathbf{2 0 1 1}$ & $\mathbf{2 0 1 2}$ \\
\hline $\begin{array}{l}\text { Total Patient Visits } \\
\text { Gender }\end{array}$ & 5,236 & 7,117 & 10,916 & 15,563 & 18,196 \\
Female & & & & 12,398 & 14,130 \\
\hline
\end{tabular}


Table 2. (continued.)

\begin{tabular}{llllll}
\hline & $\mathbf{2 0 0 8}$ & $\mathbf{2 0 0 9}$ & $\mathbf{2 0 1 0}$ & $\mathbf{2 0 1 1}$ & $\mathbf{2 0 1 2}$ \\
\hline Male & 1,119 & 1,748 & 2,295 & 3,165 & 4,066 \\
Patient Type & & & & 1,032 & 1,153 \\
Cancer & 1,361 & 1,047 & 1,239 & 14,531 & 17,043 \\
Non-Cancer & 3,875 & 6,070 & 9,918 & & 10,191 \\
Modality & & & & 3,477 & 30 \\
Massage & 3,560 & 4,083 & 6,556 & 43 & 1,030 \\
Guided Imagery & 73 & 38 & 36 & 799 & 189 \\
Naturopath & 126 & 273 & 520 & 158 & 6,515 \\
Reiki & 151 & 129 & 118 & 5,916 & 124 \\
Acupuncture & 1,326 & 2,421 & 3,461 & 170 & 117 \\
CST & 0 & 21 & 225 & 0 & \\
Medical Facial & 0 & 0 & 0 & & \\
\hline
\end{tabular}

Note. CST - cranial sacral therapy. These numbers do not include inpatient and infusion center massage, oncology massage by externs, or Reiki performed by our volunteer Reiki program.

\subsection{Making sense of the cents}

When designing a new program at any institution, strategic planning is a key component in trying to understand the business model and the local competition. With the changing environment with healthcare reform and the need to address wellness and prevention in all patients, IM has come to the forefront as an option to address these issues. The main issue with this type of service is that healthcare systems have been tasked with trying to deliver a service without reimbursement from insurance carriers. When the initial discussions regarding the implementation of an IM program occurred, the financial model was discussed at length. Due to the fact at the time that no insurance plans covered these services, the team needed to be creative in developing a model that was self-sustaining for the foreseeable future. The health system decided to use a cash model when care was delivered for any IM service. IM is one of a handful of departments in the system that does not accept insurance due to the fact that there currently is very little reimbursement for IM services. However, our health system has its own insurance program that is offered to employees and their families, and some IM services are covered under this insurance plan. Therefore, our employees can access IM services with a minor co-pay. This outcome is a result of providing clinical data over the years and providing safe, effective, evidence-based holistic care. With the advent of health care reform we may find that more IM services will be covered as many CAM modalities have been found to be cost-effective compared to traditional therapy ${ }^{[13]}$.

When discussing this type of service with leaders, there is a prevailing misconception that IM programs generate substantial revenue. For any service in a health system, the goal is for the service to bring additional revenue to the hospital's bottom line; however, the institution must commit to share in the program start-up costs. Although it is true that IM programs can bring in significant cash revenue, they also have very high expenses associated with staffing. Similar to most clinical programs in any department, the staff is certified in their respective specialty to provide the highest quality of care to patients. For the service to generate positive returns, the clinical volume must remain high on a day-to-day basis. This translates to having multiple providers providing services throughout the day with few cancellations. Although the services are valued by patients, it is a very time-intensive business, such that one patient visit equates to one hour of service regardless of what service is being provided. This business model does not allow for wide variability in delivering positive financial outcomes. To be considered financially successful, most programs are looking to break even on the services they provide. By diversifying the business model to include such things as a retail store for certified herbs and supplements, guided imagery CDs, yoga mats, and candles, an IM program can begin to realize positive contribution to margins. To break even in this business is to be considered very successful. 
Another avenue that allows programs to remain financially viable is through philanthropy. Many programs start with an endowment or some type of seed money that is either provided by the healthcare system or philanthropy. This program was very fortunate to begin with a $\$ 60,000$ donation to the Oncology Department; however, it was quickly realized that the patients who benefited from the care they received wanted to give back through financial donations. Within a seven-year period, the program received over $\$ 400,000$ in financial gifts from individual patients. This money has been used to help support the program through new initiatives and support staff. Opportunities for stewardship with potential donors continue to help support the program.

\section{Evidence of program success}

The IM program at Beaumont Health System has been considered a resounding success. The marked increase in utilization indicates that the services provided by the IM department are in demand, with over 18,000 patient visits in 2012 (see Table 2). Furthermore, the program has expanded substantially since its inception. The program now offers 11 of different CAM services and employs 52 CAM practitioners (see Table 1). In addition to expanding within the main hospital, IM is now offered in seven different clinics. Although patient satisfaction is not measured in our IM department in the same way as it is in the hospital, we have received numerous testimonials from grateful patients, physician, donors, and medical staff regarding their experiences with the IM program. In addition, the IM program has received philanthropic donations (to date, $\$ 400,000$ ) from grateful patients who wish to support the program, thus indicating their approval and success of the program.

Financially, the IM department has become self-sufficient and no longer requires financial support from other hospital departments. Initially, the department required seed money to begin and work to grow to its current state. In 2012, IM department was able to generate $\$ 1.94$ million in total revenue and had expenses totaling $\$ 1.87$ million and a positive operating margin $(\$ 70,547)$. The largest expense for the department was labor, which totaled $\$ 1.417$ million or $75.6 \%$ of the total expense. Unfortunately there are few opportunities to reduce program costs; however, there are additional ways to increase sales, primarily through supplements and merchandise. The other program benefit that is not reflected in these values is the benefit it provides to the employee health plan. The IM program has provided an alternative to expensive treatments and has allowed members to stay within the healthcare system while reducing the health plans costs. To have a self-sustaining IM department indicates the program success.

\section{Conclusions}

Developing an IM program in a large hospital system is very time intensive and has unique challenges however our experience has proven to be very rewarding for IM practitioners, hospital staff, and patients. In addition, it has been our experience that an IM program can be financially viable. However, the positive impact for the hospital goes well beyond the money. Programs of this type are well received by patients and may create loyalty to the hospital.

Our IM program has been very fortunate to have high-level support and accepting medical professionals. Nine years after initiation, we are a thriving department, embraced by patients in multiple geographic areas.

If our biggest problem is that we are growing out of our space, then we should consider ourselves very lucky. We look forward to continuing to offer our patients the very best holistic care and continuing to expand our CAM modality offerings. A strong IM program teamed up with a hospital offering excellent, cutting-edge medical care is truly an organization that can treat the whole patient - body, mind, and spirit!

\section{Competing interests}

The authors declare that they have no competing interests. 


\section{Acknowledgements}

We thank Christine Billecke, Ph.D. for her editorial assistance in the preparation of this manuscript.

\section{References}

[1] Diehl, V. The bridge between patient and doctor: the shift from CAM to integrative medicine. Hematology Am Soc Hematol Educ Program. 2009; 320-325. http://dx.doi.org/10.1182/asheducation-2009.1.320

[2] Vohra, S., Feldman, K., Johnston, B., Waters, K., Boon, H. Integrating complementary and alternative medicine into academic medical centers: experience and perceptions of nine leading centers in North America. BMC Health Serv Res. 2005 ; 5: 78. http://dx.doi.org/10.1186/1472-6963-5-78

[3] Ananth, S. 2010 Complementary and alternative medicine survey of hospitals. Alexandria, VA: Samueli Institute. 2011.

[4] Coulter, I. D., Ellison, M. A., Hilton, L., Rhodes, H. J., Ryan, G. W. Hospital-based integrative medicine: a case study of the barriers and factors facilitating the creation of a center. Santa Monica, CA: RAND Corporation. 2007.

[5] Colvin, G. Walter Robb: Whole Foods' other CEO on organic growth. CNN Money. Retrieved 08/20/2013, 2013.

[6] Barnes, P. M., Bloom, B., Nahin, R. L. Complementary and alternative medicine use among adults and children: United States, 2007. Natl Health Stat Report. 2008; 12: 1-23. PMid: 19361005.

[7] Thompson, D., Aronson, S. Case studies of integrative medicine and medical spa programs at community hospitals. Washington, D.C. 2008.

[8] Cassileth, B. R. Integrative oncology in the United States: Memorial Sloan-Kettering Cancer Center programme as prototype. Psycho-Oncol. 2011; 5: 152-156. http://dx.doi.org/10.1007/s11839-011-0325-3

[9] Boon, H. S., Kachan, N. Integrative medicine: a tale of two clinics. BMC Complement Altern Med. 2008 ; 8: 32. http://dx.doi.org/10.1186/1472-6882-8-32

[10] Green, J., Roy, S. The role of natural medicine and complementary care in oncology services. Integrative Medicine. Beaumont Health System. 2013.

[11] Armstrong, K. Medical Massage. Massage Magazine. October 2013; 52-56.

[12] MHADegree.org. Top 50 Most Social Media Friendly Hospitals for 2013. 2013.

[13] Herman, P. M., Poindexter, B. L., Witt, C. M., Eisenberg, D. M. Are complementary therapies and integrative care cost-effective? A systematic review of economic evaluations. BMJ Open. 2012; 2(5). http://dx.doi.org/10.1136/bmjopen-2012-001046 